\title{
COMPARISON RESULTS FOR PARABOLIC \\ DIFFERENTIAL EQUATIONS AT RESONANCE
}

by

\begin{abstract}
G. R. Shendge ${ }^{*}$ Department of Mathematics The University of Texas Arlington, Texas 76019
\end{abstract}

\author{
A. S. Vatsala \\ Department of Mathematics \\ Bishop College \\ 3837 Simpson-Stuart Road \\ Da11as, Texas 75241
}

Technical Report No. 188

July 1982

+ Research partlally supported by U. S. Army Research Grant \#DAAG29-81-G-0008.

* On study leave from the Department of Mathematics and Statistics, Marathwada University, Aurangabad 431004, Maharashtra, India. 
COMPARTSON RESULTS FOR PARABOLTC DIFFERENTTAL

EQUATIONS AT RESONANCE

by

G. R. Shendge and A. S. Vatsala

1. It is very we11 known that comparison princtples for Inttial and boundary value problems for nonresonance cases have been very much. used in the existence of solutions and the development of the monotone method $[1,2,3,4,5,9]$. These comparison techniques do not cover the resonance cases. Hence it 18 of practical interest to look at such resulte for resonance cases. With this view, differert comparison results were recently developed for first and gecond order periodlc boundary value problems [10]. Some spectal cases of thege have been used in $[6,7]$ and in developing the monotone method for first order periodlc systems in [11]. In this paper we develop systematically general comparlson techniques for semilinear parabolic equathons with pertodtc and homogeneous Neumann boundary condttons, since:spectal cases of such equations occur in many phystcal sttuations as reaction diffusion equations $[5,8]$.

2. Constder the perlodic boundary value problem (PBvp for short).

$$
\begin{aligned}
& u_{t}-u_{x x}=g\left(t, x, u_{x} u_{x}\right), 0 \leq t \leq 2 \pi, 0 \leq x \leq 1, \\
& u(0, x)=u(2 \pi, x), x \in I, u(t, 0)=u(t, 1), \\
& u_{x}(t, 0)=u_{x}(t, 1), t \in J
\end{aligned}
$$

where $g \in C[J \times J \times R \times R, R], J \approx[0,2 \pi], I=(0,1]$. For convenience we 11st the following condtions for functions $m, B, z \in C^{1,2}[J \times I, R]$.

$$
\begin{aligned}
& \left(A_{0}\right) \quad m(0, x) \leq m(2 \pi, x), m(t, 0)=m(t, 1), m_{x}(t, 0) \geq m_{x}(t, 1) \\
& \quad \text { and } m_{t}-m_{x x} \leq g\left(t, x, m, m_{x}\right), 0<t \leq 2 \pi, 0 \leq x \leq 1 \\
& \left(A_{1}\right) \quad B(0, x) \geq B(2 \pi, x), B(t, 0)=\beta(t, 1), B_{x}(t, 0) \leq \beta_{x}(t, 1) \\
& \text { and } B_{t}-B_{x x} \geq g\left(t, x, B, \beta_{x}\right), 0<t \leq 2 \pi, 0 \leq x \leq 1 .
\end{aligned}
$$


$\left(A_{2}\right)$ For any $u, v \in C^{1,2}[J \times I, R], g_{u}(t, x, u, v), g_{v}(t, x, u, v)$ are continuous, $g_{u}(t, x, u, v) \leq 0$ and for any ftxed $t_{0} \quad g_{u}(t, x, u, v) \neq 0$.

$\left(A_{3}\right) z(t, x)>0$ on $J \times I, z(0, x) \geq z(2 \pi, x), z(t, 0)=z(t, 1), \quad z_{x}(t, 0) \leq z(t, 1)$ and for every $\lambda>0$, elther

(1) $\lambda\left(z_{t}-z_{x x}\right)>g\left(t, x, \beta+\lambda z, \beta_{x}+\lambda z_{x}\right)-g\left(t, x, \beta_{3} \beta_{x}\right)$ on $J x t$; or

(11) $\lambda\left(z_{t}-z_{x x}\right)>g\left(t, x, m, m_{x}\right): g\left(t, x, m-\lambda z, m_{x}-\lambda z_{x}\right)$ on $J \times I$.

Let $v \in C^{1,2}[J \times I, R]$. Then a function $G(t, x, u, w)$ is sald to be a modifled

function relative to $v$ if

$$
G(t, x, u, w)=g(t, x, p(t, x, u), w)+\frac{p(t, x, u)-u}{1+u^{2}}
$$

where $p(t, x, u)=\max (v(t, x), u)$.

Let us begin by proving the following theorem.

Theorem 2.1. Constder the PBVP $(2.1),(2.2)$. Assume that:

(1) .: the modiffed PBVP

$$
\begin{aligned}
& u_{t}-u_{x x}=G\left(t, x, u, u_{x}\right), 0 \leq t \leq 2 \pi, 0 \leq x \leq 1 \\
& u(0, x)=u(2 \pi, x), x \in I, u(t, 0)=u(t, 1) \\
& u_{x}(t, 0)=u_{x}(t, 1), t \in J
\end{aligned}
$$

admits a solution $u$ for every lower solution $v$ of (2.1);

(11) $r(t, x)$ to the maximal solution of the PBVP $(2.1),(2.2)$ on $J \times I$.

Then $\left(A_{0}\right)$ timplies $m(t, x) \leq r(t, x)$ on $J \times I$.

Proof. Let $u(t, x)$ be a solution of the pBVp $(2.3),(2.4)$, where the modifled

function $G$ is defined relative to $m$. It is enough to prove that $m(t, x) \leq u(t, x)$

on $J \times I$ : Suppose this is not true. Then there exists an $M>0$ and a $\left(t_{0}, x_{0}\right) \in J \times I$ such that 


$$
m\left(t_{0}, x_{0}\right)=u\left(t_{0}, x_{0}\right)+M, m\left(t_{s}, x\right) \leq u(t, x)+M \text { on } J \times I .
$$

If $\left(t_{0}, x_{0}\right) \in(0,2 \pi) \times(0,1)$, then we have $m_{t}=u_{t}, m_{x}=u_{x}$ and $m_{x x} \leq u_{x x}$ at $\left(t_{0}, x_{0}\right)$. Moreover, since $m\left(t_{0}, x_{0}\right)>u\left(t_{0}, x_{0}\right)$, we a1so have $p\left(t_{0}, x_{0}, u\right)=m\left(t_{0}, x_{0}\right)$. Consequent1y, by $(2.3)$ and the definition of $G$, we have

$$
\begin{aligned}
m_{t}\left(t_{0}, x_{0}\right)-m_{x x}\left(t_{0}, x_{0}\right) & \geq u_{t}\left(t_{0}, x_{0}\right)-u_{x x}\left(t_{0}, x_{0}\right) \\
& =G\left(t_{0}, x_{0}, u\left(t_{0}, x_{0}\right), u_{x}\left(t_{0}, x_{0}\right)\right) \\
& =g\left(t_{0}, x_{0}, m\left(t_{0}, x_{0}\right), m_{x}\left(t_{0}, x_{0}\right)\right)+\frac{m\left(t_{0}, x_{0}\right)-u\left(t_{0}, x_{0}\right)}{1+u\left(t_{0}, x_{0}\right)} \\
& >g\left(t_{0}, x_{0}, m\left(t_{0}, x_{0}\right), m_{x}\left(t_{0}, x_{0}\right)\right)
\end{aligned}
$$

contradicting $\left(A_{0}\right)$.

If $t_{0}=2 \pi$ and $x_{0} \in(0,1)$, then from (2.5), we get

$$
m_{t} \geq u_{t} \text { and } m_{x}=u_{x} \text { at }\left(2 \pi, x_{0}\right)
$$

Also if $t_{0}=0$ and $x_{0} \in(0,1)$, we get

$$
m\left(2 \pi, x_{0}\right) \geq m\left(0, x_{0}\right)=u\left(0, x_{0}\right)+M=u\left(2 \pi, x_{0}\right)+M
$$

by $(2.5)$ and $\left(A_{0}\right)$. As a result we again get $(2.6)$ from $(2.5)$. Hence if $t_{0}=0$ or $2 \pi$ and $x_{0} \in(0,1)$, we have $m_{t} \geq u_{t}, m_{x}=u_{x}$ and $m_{x x} \leq u_{x x}$ at $\left(2 \pi, x_{0}\right)$. These relations lead to a contradiction to $\left(\Lambda_{0}\right)$ as before.

Suppose next that $t_{0} \in(0,2 \pi)$ and $x_{0}=1,1=0,1$. Then from $(2.5)$ we obtain

$$
m_{t}\left(t_{0}, 1\right) \geq u_{t}\left(t_{0}, 1\right), m_{x}\left(t_{0}, 0\right) \leq u_{x}\left(t_{0}, 0\right), m_{x}\left(t_{0}, 1\right) \geq u_{x}\left(t_{0}, 1\right)
$$

A1so, if $t_{0}=0$ and $x_{0}=1$, we get

$$
m(2 \pi, 1) \geq m(0,1)=u(0,1)+M=u(2 \pi, 1)+M
$$


by $(2.5)$ and $\left(A_{0}\right)$. Consequently we obtaln

$$
m_{t}(2 \pi, 1) \geq u_{t}(2 \pi, 1), m_{x}(2 \pi, 0) \leq u_{x}(2 \pi, 0), m_{x}(2 \pi, 1) \geq u_{x}(2 \pi, 1)
$$

by $(2.5)$. Now if $\left(A_{0}\right)$ holds, then $(2.4)$ and $(2.7)$ yleld

$$
m_{x}\left(t_{0}, 1\right)=u_{x}\left(t_{0}, 1\right)
$$

Hence if $t_{0} \in(0,2 \mu]$ and $x_{0}=1$, we have $m_{t} \geq u_{t}, m_{x}=u_{x}$ and $m_{x x} \leq u_{x x}$ at $\left(t_{0}, 1\right)$. These relations lead to a contradiction as before. A stmilar contradiction results from (2.8) if $t_{0}=0$ and $x_{0}=1$. Thus if $\left(A_{0}\right)$ holds, we have $m(t, x) \leq u(t, x)$ on $J \times T$. But then $1 t$ follows from the definition of $G$ that $u(t, x)$ is actually a solution of the plsvp (2.1), (2.2), and since $u(t, x) \leq r(t, x)$ on $J \times I$, the proof of the theroem $1 \mathrm{~s}$ complete.

We shall prove next a theorem which deals with the upper and lower solutlons of the pBvp (2.1), (2.2).

Theorem 2.2. Let $\left(A_{1}\right)$ and $\left(A_{2}\right)$ hold. Then $\left(A_{0}\right)$ imp1les $m(t, x) \leq B(t, x)$ on $J \times I$.

Proof. We show first that if one of the inequalities in $\left(A_{1}\right)$ and $\left(A_{0}\right)$ is strtct, then $m(t, x)<B(t, x)$ on $J \times T$. If not, there exists a $\left(t_{0}, x_{0}\right) \in J \times I$ and an $M \geq 0$ such that

$$
m\left(t_{0}, x_{0}\right)-\beta\left(t_{0}, x_{0}\right)=M \text { and } m(t, x)-\beta(t, x) \leq M \text { on } J \times 1 \text {. }
$$

If $t_{0} \in(0,2 \pi)$ and $x_{0} \in(0,1)$, then we have $m_{t}=\beta_{t}, m_{x}=\beta_{x}$ and $m_{x x} \leq \beta_{x x}$ at $\left(t_{0}, x_{0}\right)$. Consequerit $1 y$

$$
\begin{gathered}
m_{x x}-\beta_{x x}>m_{t}-g\left(t_{0}, x_{0}, m_{,} m_{x}\right)-\beta_{t}+g\left(t_{0}, x_{0}, \beta, \beta_{x}\right) \\
\quad=g_{u}\left(t_{0}, x_{0}, \xi, \beta_{x}\right)(-M) \geq 0
\end{gathered}
$$


where $\xi$ is a point between $m\left(t_{0}, x_{0}\right)$ and $B\left(t_{0}, x_{0}\right)$. Thus we get

$$
m_{x x}-\beta_{x x}>0 \text { at }\left(t_{0}, x_{0}\right)
$$

which is a contradiction to the definftion of $\left(t_{0}, x_{0}\right)$.

suppase next that $t_{0}=2 \pi$ and $x_{0} \in(0,1)$. Then from (2.10) we obtaln

$$
m_{t}\left(2 \pi, x_{0}\right) \geq \beta_{t}\left(2 \pi, x_{0}\right) \text { and } m_{x}\left(2 \pi, x_{0}\right)=\beta_{x}\left(2 \pi, x_{0}\right)
$$

If, on the other hand $t_{0}=0$ and $x_{0} \in(0,1)$, we have by $(2.10)$ and $\left(A_{0}\right)$

$$
m\left(2 \pi, x_{0}\right) \geq m\left(0, x_{0}\right)=B\left(0, x_{0}\right)+M \geq \beta\left(2 \pi, x_{0}\right)+M
$$

As a resu1t, we again get (2.12). Hence if $t_{0}=0$ or $2 \pi$ and $x_{0} \in(0,1)$, we are led to the Inequality $(2.11)$ at $\left(2 \pi, x_{0}\right)$, which is a contradiction. Suppose next that $t_{0} \in(0,2 \pi]$ and $x_{0}=1,1=0,1$. Then from $(2.10)$ we get

$$
\left\{\begin{array}{l}
m_{t}\left(t_{0}, 1\right) \geq \beta_{t}\left(t_{0}, 1\right), m_{x}\left(t_{0}, 0\right) \leq \beta_{x}\left(t_{0}, 0\right) \\
\text { and } m_{x}\left(t_{0}, 1\right) \geq \beta_{x}\left(t_{0}, 1\right)
\end{array}\right.
$$

If, on the other hand, $t_{0}=0$ and $x_{0}=1,1=0,1$, we have

$$
m(2 \pi, 1) \geq m(0,1)=\beta(0,1)+M \geq B(2 \pi, 1)+M .
$$

As a regult we get

$$
\left\{\begin{array}{l}
m_{t}(2 \pi, 1) \geq \beta_{t}(2 \pi, 1), m_{x}(2 \pi, 0) \leq \beta_{x}(2 \pi, 0) \\
\text { and } m_{x}(2 \pi, 1) \geq \beta_{x}(2 \pi, 1)
\end{array}\right.
$$

by $(2.10)$. Hence if $\left(A_{0}\right)$ holds, we get

$$
m_{x}\left(t_{0}, 1\right)=\beta_{x}\left(t_{0}, t\right), 1=0,1
$$


by $(2.13)$ and $\left(A_{1}\right)$. Consequently we are led to the inequality $(2.11)$ at $\left(t_{0}, 1\right)$, which la a contradiction. If $t_{0}=0$ and $x_{0}=1$, a simflar contradiction follows from $(2.14)$ at $(2 \pi, 1)$. Thts proves that $m(t, x)<B(t, x)$ on $J \times I$ if $\left(A_{0}\right)$ holds and one of the Inequalities in $\left(A_{0}\right)$ and $\left(A_{1}\right)$ is strict.

Let us now suppose that none of the inequalities in $\left(A_{0}\right)$ and $\left(A_{1}\right)$ is strfet. We sha11 estab11sh $m(t, x) \leq \beta(t, x)$ on $J \times 1$. If this 1 s not true, then there exlsts a point $\left(t_{0}, x_{0}\right) \in J \times I$ and a constant $M>0$ such that $(2.10)$ holds. The existence of such a $\left(t_{0}, x_{0}\right) \quad 1 n J \times I$ and $M>0$ Implies that $m\left(t_{0}, x\right)-\beta\left(t_{0}, x\right) \equiv M$ for a11 $x \in I$. If not, there extsts an $x^{*} \in[0,1]$ such that $m\left(t_{0}, x^{*}\right)-\beta\left(t_{0}, x^{*}\right)<M$. Suppose that $t_{0} \in(0,2 \pi]$ and $x_{0} \in(0,1)$. Let $x^{*} \in\left(x_{0}, 11\right.$. Define $z(x)=e^{\alpha\left(x-x_{0}\right)}-1, x \in I$. Note that $z(x)<0$ for $x \in\left[0, x_{0}\right), z\left(x_{0}\right)=0$ and $z(x)>0$ for $x \in\left(x_{0}, 1\right]$. Consider now a function

$$
W(x)=m\left(t_{0}, x\right)-\beta\left(t_{0}, x\right)+\varepsilon z(x), x \in I,
$$

where we choose $\varepsilon>0$ so that

$$
0<E<\frac{M-\left[m\left(t_{0}, x^{*}\right)-B\left(t_{0}, x^{*}\right)\right]}{z\left(x^{*}\right)} .
$$

Clearly such a cholce $1 \mathrm{~s}$ posstble because $z\left(x^{*}\right)>0$ and $M>m\left(t_{0}, x^{*}\right)-B\left(t_{0}, x^{*}\right)$. Using $\left(A_{0}\right)$ and $\left(A_{1}\right)$, we obtain for $x \in I$

$$
\begin{aligned}
W^{\prime \prime}(x) & =m_{x x}\left(t_{0}, x\right)-\beta_{x x}\left(t_{0}, x\right)+\epsilon z^{\prime \prime}(x),\left(\equiv \frac{d}{d x}\right), \\
& \geq g_{u}\left(t_{0}, x, \xi, n\right)\left[\beta\left(t_{0}, x\right)-m\left(t_{0}, x\right)\right] \\
& +g_{u_{x}}\left(t_{0}, x, \xi, \eta\right)\left[\beta_{x}\left(t_{0}, x\right)-m_{x}\left(t_{0}, x\right)\right] \\
& +\left[m_{t}\left(t_{0}, x\right)-\beta_{t}\left(t_{0}, x\right)\right]+\varepsilon z^{\prime \prime}(x),
\end{aligned}
$$

where $\xi$ is a point between $\mathrm{m}\left(t_{0}, x\right)$ and $\beta\left(t_{0}, x\right)$ and $\eta$ is a point between $\mathrm{m}_{\mathrm{x}}\left(\mathrm{t}_{0}, \mathrm{x}\right)$ and $\beta_{\mathrm{x}}\left(t_{0}, \mathrm{x}\right)$. By $(2.16)$ this Implies that for $x \geq \mathrm{x}_{0}$ 


$$
\begin{aligned}
W^{\prime \prime}(x) & \geq-g_{u}\left(t_{0}, x, \xi, n\right) W(x)-g_{u}\left(t_{0}, x, \xi, n\right) W^{\prime}(x) \\
& -\varepsilon g_{u}\left(t_{0}, x, \xi, n\right) \\
& +\left[\varepsilon\left[g_{u}\left(t_{0}, x, \xi, n\right)+\alpha g_{u}\left(t_{0}, x, \xi, n\right)+\alpha^{2}\right] e^{\alpha\left(x-x_{0}\right)}\right. \\
& \left.+\left[m_{t}\left(t_{0}, x\right)-\beta_{t}\left(t_{0}, x\right)\right]\right] .
\end{aligned}
$$

We now choose $\alpha>0$ so that

$$
\left[g_{u}\left(t_{0}, x, \xi, \eta\right)+\alpha g_{u_{x}}\left(t_{0}, x, \xi, \eta\right)+\alpha^{2}\right]>0
$$

Such a cholce $1 \mathrm{~s}$ posstble because $g_{u}\left(t_{0}, x, \xi, n\right)$ and $g_{u_{x}}\left(t_{0}, x, \xi, n\right)$ are bounded on $J \times I_{0}$ Hence using the facts that $g_{u} \leq 0$ and $m_{t}\left(t_{0}, x\right) \geq B_{t}\left(t_{0}, x\right)$, we get

$$
W^{\prime \prime}(x)>-g_{u}\left(t_{0}, x, \xi, \eta\right) W(x)-g_{u}\left(t_{0}, x, \xi_{5}, \eta\right) W^{\prime}(x)
$$

for $x \in\left[x_{0}, 1\right]$. However, from the relations $W\left(x_{0}\right)=M, W\left(x^{*}\right)<M$ and $z(x)>0$ for $x \in\left(x_{0}, 1\right]$, it follows that there exists a point $\tilde{x} \in\left[x_{0}, x^{*}\right)$ at which $W$ has a maximum $N \geq M>0$. Then $W(\tilde{x})=N \geq M>0$, and since $\tilde{x} \in(0,1)$, we have $W^{\prime}(\tilde{x})=0$ and $W^{\prime \prime}(\tilde{x}) \leq 0$. But since $g_{u}\left(t_{0}, x, \xi, n\right) \leq 0$, $(2.17)$ Implies $W^{\prime \prime}(\tilde{x})>0$, which is a contradlction. Suppose next that $t_{0} \in(0,2 \pi]$ and $x_{0}=0$. Then From $(2.10)$ we get

$$
\mathrm{m}_{x}\left(t_{0}, 0\right) \leq \beta_{x}\left(t_{0}, 0\right) \text { and } m_{x}\left(t_{0} ; 1\right) \geq \beta_{x}\left(t_{0}, 1\right)
$$

If $\left(A_{0}\right)$ holds, then $(2.18)$ together with $B_{x}\left(t_{0}, 0\right) \leq B_{x}\left(t_{0}, 1\right)$ imp11es

$$
m_{x}\left(t_{0}, 1\right)=\beta_{x}\left(t_{0}, 1\right), i=0,1 \text {. }
$$

Consequent1y. $W^{\prime}(0)=m_{x}\left(t_{0}, 0\right)-\beta_{x}\left(t_{0}, 0\right)+\varepsilon \alpha=\varepsilon \alpha>0$. Now the relat Lons $W(0)=M, W\left(x^{*}\right)<M$ where $x^{*} \in(0,1]$ and $W^{\prime}(0)>0$ show that there exists a point $\tilde{x} \in\left(0, x^{*}\right)$ at which $W$ has a maximum $N \geq M>0$, contradtcting (2.17), 
which now holds on $[0,1]$. If $t_{0} \in(0,2 \pi]$ and $x_{0}=1$, taking the auxiliary function $z(x)=e^{-\alpha\left(x-x_{0}\right)}-1$, where $\alpha>0$ is chosen properly and following the above argument we again arrive at a contradiction. If $x^{\star} \in\left[0, x_{0}\right)$, we take the auxiliary function $z(x)=e^{\alpha\left(x_{0}-x\right)}-1$ and follow sinilar argument. Thus in a11 possible cases we have shown that $m\left(t_{0}, x\right)-B\left(t_{0}, x\right) \equiv M$ on $I$ whenever we have $(2.10)$. Consequently we get for ail $x \in I$

$$
0 \equiv m_{x x}\left(t_{0}, x\right)-\beta_{x x}\left(t_{0}, x\right) \geq g_{u}\left(t_{0}, x, \xi, m_{x}\right)(-M) \geq 0
$$

by $\left(A_{0}\right)$ and $\left(A_{1}\right)$, where $\xi=\xi\left(t_{0}, x\right)$ is a point between $m\left(t_{0}, x\right)$ and $B\left(t_{0}, x\right)$. Since $M>0$, it follows from the above inequality that $g_{u}\left(t_{0}, x, \xi\left(t_{0}, x\right), m_{x}\left(t_{0}, x\right)\right) \equiv 0$ for $a 11 x \in I$, which contradicts the hypothesis $\left(A_{2}\right)$. Th1s proves that we have $m\left(t_{0}, x\right)-B\left(t_{0}, x\right) \equiv M$ on $T$, which then leads to a contradiction as before. Therefore, $m(t, x) \leq \beta(t, x)$ on $J \times 1$ and the proof of the theorem is complete.

Theorem 2.3. The assertion of Theorem 2.2 remalns valid if $\left(A_{2}\right)$ is replaced by $\left(A_{3}\right)(1)$

Proof. Suppose that $m(t, x) \leq \beta(t, x),(t, x) \in J \times I$ is not true. Then we can find a minima $1 \lambda>0$ and $a\left(t_{0}, x_{0}\right) \in J \times 1$ such that

$$
\left\{\begin{array}{l}
m\left(t_{0}, x_{0}\right)=\beta\left(t_{0}, x_{0}\right)+\lambda z\left(t_{0}, x_{0}\right), \text { and } \\
m(t, x) \leq \beta(t, x)+\lambda z(t, x),(t, x) \in J \times I .
\end{array}\right.
$$

If $\left(t_{0}, x_{0}\right) \in(0,2 \pi) \times(0,1)$, we have

$$
m_{t}=\beta_{t}+\lambda z_{t}, m_{x}=\beta_{x}+\lambda z_{x} \text { and } m_{x x} \leq \beta_{x x}+\lambda z_{x x}
$$

at : $\left(t_{0}, x_{0}\right)$. Hence by $\left(A_{1}\right)$ and $\left(A_{3}\right)(1)$, we get at $\left(t_{0}, x_{0}\right)$ 


$$
\begin{aligned}
m_{t}-m_{x x} \geq & \beta_{t}-\beta_{x x}+\lambda\left(z_{t}-z_{x x}\right) \\
& >g\left(t_{0}, x_{0}, \beta, \beta_{x}\right) \\
& +g\left(t_{0}, x_{0}, \beta+\lambda z, \beta_{x}+\lambda z_{x}\right) \\
& -g\left(t_{0}, x_{0}, \beta, \beta_{x}\right) .
\end{aligned}
$$

That 1s

$$
m_{t}-m_{x x}>g\left(t_{0}, x_{0}, m_{,} m_{x}\right) \text { at }\left(t_{0}, x_{0}\right)
$$

contradicting $\left(A_{0}\right)$.

Suppose next that $t_{0}=2 \pi$ and $x_{0} \in(0,1)$. Then from $(2.20)$ we get

$$
\left\{\begin{array}{l}
m_{t}\left(2 \pi, x_{0}\right) \geq \beta_{t}\left(2 \pi, x_{0}\right)+\lambda z_{t}\left(2 \pi, x_{0}\right), \text { and } \\
m_{x}\left(2 \pi, x_{0}\right)=\beta_{x}\left(2 \pi, x_{0}\right)+\lambda z_{x}\left(2 \pi, x_{0}\right)
\end{array}\right.
$$

A1so, tf $t_{0}=0$ and $x_{0} \in(0,1)$ we obtatn, using $(2,20)$ the Inequality

$$
m\left(2 \pi, x_{0}\right) \geq m\left(0, x_{0}\right)=\beta\left(0, x_{0}\right)+\lambda z\left(0, x_{0}\right) \geq B\left(2 \pi, x_{0}\right)+\lambda z\left(2 \pi, x_{0}\right) .
$$

As a result, we again get $(2.21)$ from $(2.20)$. Hence if $t_{0}=0$ or $2 \pi$ and $x_{0} \in(0,1)$, we get

$$
m_{t}-m_{x x}>g\left(2 \pi, x_{0}, m, m_{x}\right)
$$

at $\left(2 \pi, x_{0}\right)$, which is again a contradiction. Suppose next that $t_{0} \in:(0,2 \pi]$ and $x_{0}=1,1=0,1$. Then from $(2.20)$ we get

$$
\left\{\begin{array}{l}
m_{t}\left(t_{0}, 1\right) \geq \beta_{t}\left(t_{0}, 1\right)+\lambda z_{t}\left(t_{0}, 1\right), \\
m_{x}\left(t_{0}, 0\right) \leq \beta_{x}\left(t_{0}, 0\right)+\lambda z_{x}\left(t_{0}, 0\right), \text { and } \\
m_{x}\left(t_{0}, 1\right) \geq \beta_{x}\left(t_{0}, 1\right)+\lambda z_{x}\left(t_{0}, 1\right)
\end{array}\right.
$$

Also if $t_{0}=0$ and $x_{0}=1$, we obtaln from $(2.20)$

$$
m(2 \pi, 1) \geq m(0,1)=B(0,1)+\lambda z(0,1) \geq B(2 \pi, 1)+\lambda z(2 \pi, 1) .
$$


Consequent 1y, using $(2.20)$, we get

$$
\left\{\begin{array}{l}
m_{t}(2 \pi, 1) \geq \beta_{t}(2 \pi, 1)+\lambda z_{t}(2 \pi, 1), \\
m_{x}(2 \pi, 0) \leq \beta_{x}(2 \pi, 0)+\lambda z_{x}(2 \pi, 0), \text { and } \\
m_{x}(2 \pi, 1) \geq \beta_{x}(2 \pi, 1)+\lambda z_{x}(2 \pi, 1)
\end{array}\right.
$$

Now if $\left(A_{0}\right)$ holds; $(2.22),\left(A_{1}\right)$ and $\left(A_{3}\right)(1)$ imply

$$
m_{x}\left(t_{0}, 1\right)=\beta_{x}\left(t_{0}, 1\right)+\lambda z_{x}\left(t_{0}, 1\right), 1=0,1
$$

which leads to

$$
m_{t}-m_{x x}>g\left(t_{0}, 1, m_{,} m_{x}\right) \text { at }\left(t_{0}, 1\right)
$$

which is a contradiction. A simflar contradiction results from (2.23) 1f $t_{0}=0$ and $x_{0}=1$. The proof of the theorem is complete.

Theorem 2.4. The assertation of Theorem 2.3 rematns valid if $\left(A_{3}\right)(1)$ is replaced by $\left(A_{3}\right)(11)$.

The proof follows by arguments simflar to those in Theorem 2.3 and hence omfted.

We shal1 next consider equation $(2.1)$ with the homogeneous Neumann boundary condittons

$$
u(0, x)=u(2 \pi, x), x \in I, u_{x}(t, 0)=u_{x}(t, 1)=0, t \in J
$$

Compartson results analogous to those for the $\operatorname{PBVP}(2.1),(2.2)$ can be proved For the BVP $(2.1),(2.2 \mathrm{~N})$. But to avold monotony, we sha11 only state the analogous theorems and onit the proofs.

We need the following conditions for functions in, $\beta, z \in C^{1,2}[J \times 1, R]$. 


$$
\begin{aligned}
& \left(B_{0}\right) \quad m(0, x) \leq m(2 \pi, x), m_{x}(t, 0) \geq 0, m_{x}(t, 1) \leq 0 \text { and } \\
& m_{t}-m_{x x} \leq g\left(t, x, m_{x} m_{x}\right) \text { on }(0,2 \pi] \times[0,1] \text {. } \\
& \left(B_{1}\right): \quad \beta(0, x) \geq \beta(2 \pi, x), \beta_{x}(t, 0) \leq 0, \beta_{x}(t, 1) \geq 0 \text { and } \\
& \beta_{t}-\beta_{x x} \geq g\left(t, x, \beta, \beta_{x}\right) \text { on }(0,2 \pi] \times[0,1] \text {. } \\
& \left(B_{2}\right), \quad \text { Same as }\left(A_{2}\right) \\
& \left(B_{3}\right) \quad z(t, x)>0 \text { on } J \times I, z(0, x) \geq z(2 \pi, x) \text {, } \\
& z_{x}(t, 0) \leq 0, z_{x}(t, 1) \geq 0 \text { and for every } \lambda>0 \text { satisfies } \\
& \text { (1) } \lambda\left(z_{t}-z_{x x}\right)>g\left(t, x, \beta+\lambda z, \dot{\beta}_{x}+\lambda z_{x}\right) \\
& -g\left(t, x, \beta, \beta_{x}\right) \text { on } J \times 1 \text {, } \\
& \text { (i1) } \lambda\left(z_{t}-z_{x x}\right)>g\left(t, x, m, m_{x}\right) \\
& -g\left(t, x, m-\lambda z, m_{x}-\lambda z z_{x}\right) \text { on } J \times T \text {. }
\end{aligned}
$$

We sha11 only state the results related to $(2.1),(2.2 \mathrm{~N})$ and the proofs follow by arguments similar to those for $(2.1),(2.2)$.

Theorem 2.5. Constder the BVP $(2.1),(2.2, N)$. Assume that the modifled BVP $(2.3),(2.2 \mathrm{~N})$ admits a solution $\mathrm{u}$ for every lower solution $v$ of $(2.1)$; $(2.2 N)$; $r(t, x)$ is the maxtmal solution of the BVP $(2.1),(2.2 \mathrm{~N})$ on $\mathrm{J} \times \mathrm{I}$. Then $\left(B_{0}\right)$ implies $m(t, x) \leq r(t, x)$ on $J \times T$.

Theorem 2.6. Let $\left(B_{1}\right)$ and $\left(B_{2}\right)$ hold. Then $\left(B_{0}\right)$ Implles that $m(t, x) \leq B(t, x)$ on $\mathrm{j} \times \mathrm{I}$.

Theorem 2.7. The assertion of Theorem 2.6 remains valld if $\left(B_{2}\right)$ is replaced by $\left(B_{3}\right)(1)$ or $\left(B_{3}\right)(11)$.

\section{ACKNOWLEDGEMENT}

The authors are grateful to Professor $V$. Lakshmtkantham for many stimulating discusstons and helpful suggestions during this work. 


\section{REFERENCES}

[1] Bernfeld, S. R. and Lakshmikantham, V.., "An Introduction to Non1inear Boundary Value Problens," Academic Press, New York, 1974.

[2] Chandra, J., Lakshmikantham, V. and Leela, S., Comparison Principle and Theory of Nonlinear Boundary Value problems, To appear in "The Proceedings of the International Conference on Nonilnear Phenomena in Mathematical Sclences," Academic press, New York, 1980.

[3] Chandra, J., Lakshmikantham, V. and Leela, S., A Monotone Method for Inf Inite Systems of Nonllnear Boundary Value Problems, Arch. Rat. Mech. Ana1., Vo1. 68 (2), $1978,179-190$.

[4] Lakshmikantham, $V_{\text {. }}$ and Leela, s. "Dtfferent1al and Integra1 Inequal1tieg," Vol. I and II, Academic Press, New York, 1969.

[5] Lakshmikantham, V., Comparison Results for Reaction-Diffusion Equations in a Banach Space, Lecture notes of talks dellvered at the conference on, "A Survey of theoretical and Numertcal Trends in Non1inear Analysts," Bari, Ita11, 1979, 121-150.

[6] Lakshmlkantham, V. and Leela, S., Existence and Monotone Method for Pertodic Solutions of First Order Differential Equations, Jour. Math. App1. (to appear

[7] Nieto-Roig, J. J., Problems at Regonance for First and Second order Different Equations via Lyapunov-1ike functions, The Univ, of Texas at Arlington, Techntcal Report No. 181, Apr 11, 1982.

[8] Pao, C. V., Asymptotfc Behav1our and Nonextstence of G1oba1 Solutions for a Class of Nonlinear Boundaty Value problems of Parabolic type, Jour. Math. Ara1. App1. 65 (1978); 616-637.

[9] Schroder, Johann, "Operator Inequalfties," Academic Press, New York, 1980.

[10] Shendge, G. R. and Vatsala, A. S., Comparison Results for First and Second Order Boundary Value Problems at Resonance, to appear In Applted Math and Computation.

(11) Vatsala, A. S., Existence of Coupled Mininal and Maxima1 Periodic QuastSolutions for Syatems of First Order Perlodic Boundary Value Problems via Quast-Solutions, to appear in The Proceedings of the Vth Internationa1 Conference on "Trends in Theory and Practice of Nonlinear Differential Equations," held at The Untveralty of Texas at Arlington, In June 1982. 